\title{
Contribution to the Study of Diversity, Distribution, and Abundance of Insect Fauna in Salt Wetlands of Setif Region, Algeria
}

\author{
Djamila Mouhoubi ${ }^{D},{ }^{1}$ Rédha Djenidi, ${ }^{2}$ and Mustapha Bounechada ${ }^{3}$ \\ ${ }^{1}$ Department of Basic Sciences, Faculty of Life and Natural Science, Lab Rescue (LADPVA), University of Setif 1, Sétif, Algeria \\ ${ }^{2}$ Faculty of Life and Natural Science and Universe and Earth Science, University of Bordj Bou-Arreridj, \\ Algeria Laboratory of Applied Biochemistry, University of Bejaia, Béjaïa 06000, Algeria \\ ${ }^{3}$ Department of Biology and Animal Physiology, Faculty of Life and Natural Science, Lab Rescue (LADPVA), \\ University of Setif 1, Sétif, Algeria \\ Correspondence should be addressed to Djamila Mouhoubi; mouhoubi_djamila@yahoo.com
}

Received 21 August 2019; Revised 5 October 2019; Accepted 2 November 2019; Published 22 November 2019

Academic Editor: Marco Cucco

Copyright (c) 2019 Djamila Mouhoubi et al. This is an open access article distributed under the Creative Commons Attribution License, which permits unrestricted use, distribution, and reproduction in any medium, provided the original work is properly cited.

\begin{abstract}
The present study aims to assess entomofauna biodiversity at three saline wetlands, located in Setif region, Northeastern Algeria. To determine the predominant environmental factors in the distribution of entomofauna, six different stations and three transects in each station were chosen according to the distribution of plant and soil salinity in each transect. Results were analysed, and different ecological indexes and analytical methods were applied, from 2016 to 2017. The total of individual insects belonging to 9 orders, 71 families, and 131 species were collected from the three sites. The highest abundance was in Coleoptera (38.17\%) while the lowest abundance was found in Ephemeroptera (1.53\%). The highest number of individuals (11438) was found in Bazer site in 2016, while the lowest number of individuals (4921) was in site Chott Frain in 2017. The highest abundance of insects (109) was recorded in transect BS1T16, and the lowest abundance of species was recorded in transect HS1T36. Diversity and equitability indices showed highest values in HS1T16 $(H=4,356)$ and HS1T37 $(E=0.7282)$. Some ecological parameters showed a significant relationship between the insects occurrence, distribution of plants, and type of soil.
\end{abstract}

\section{Introduction}

Algeria is known by its unique geographical position and its varied areas and climate. In addition to that, it has various types of natural freshwater wetlands and saline wetlands (Chott and Sebkha) and, in addition, it also contributes to the floral and faunal diversity [1]. Currently 42 out of the 300 lakes in Algeria are listed under the Ramsar Convention covering an area of 3 million ha [2]. The biodiversity values of the saline wetlands in the Sebkha Bazer and Chott Beida have been recognised by their national and international significance, as demonstrated through their listing by the Ramsar Convention on Wetlands. That is due to the outstanding diversity of their plant communities and their role in conserving the large number of animals and migration of water birds that congregate during the dry season and also rare insect species [3]. The insects are known to be the most successful and diverse animals on the earth. They have adopted for almost every conceivable type of environment from the equator to the arctic and from sea level to the snowfield of highest mountains, on land, in air, in water, and almost everywhere. The insects are considerably estimated to comprise more than 75 percent of the known species of the animals [4].

The Sebkha and Chott have various vegetation, animals, and habitats. The soil and vegetation diversity and richness indirectly affect insect species diversity and abundance $[5,6]$. The structure of vegetation between the different sites and different transects in each stations could affect the existing insect diversity. 
The most important environmental factors usually affecting insect communities are temperature (water or air), vegetation cover, and salinity (soil and water) $[6,7]$. The role of soil salinity in distribution of insects is largely unknown. Particular difficulties include absence of surveys or studies of distribution of insects in saline wetlands (Sebkha and Chott). Several studies have shown that macroinvertebrate assemblages begin to be modified when salinity ranges from 1 to $3 \mathrm{~g} / \mathrm{L}$ with a reduction of diversity and abundance [7].

The insect diversity and abundance in three saline wetlands, namely, Sebkha Bazer, Chott Beida, and Chott Frain in Setif, were studied.

The aims of our study were to characterize the distribution of insects along a salinity gradient to determine the diversity and abundance of the insects and to compare the composition and abundance of insect morphospecies in the wet and dry seasons in the three saline wetlands.

\section{Materials and Methods}

2.1. Study Area. This study was carried out in the ecocomplex of saline wetlands of the high plains of Setif in Northeastern Algeria (Figure 1). The altitude in this ecocomplex varies between 800 and $1200 \mathrm{~m}$, and the region is characterized by semiarid Mediterranean climate, hot-dry summer $\left(30-35^{\circ} \mathrm{C}\right)$ followed by cool-wet winter $\left(-2-5^{\circ} \mathrm{C}\right)$ [8]. The majority of these wetlands run dry during the dry season. The dominant substrate soil is rich in magnesium chlorides, and it only allows the development of salt-tolerant flora highly adapted, composed mainly of Chenopodiaceae (Atriplex halimus, Atriplex patula, Salsola fruticosa, and Salicornia fruticosa) and Brassicaceae (Mauricaundia arvensis, Matthiola fruticulosa, and Diplotaxis muralis) [3]. Among the three selected sites that were selected, within this eco-complex of saline wetlands, two of these wetlands are Ramsar sites: Sebkha Bazer $\left(36^{\circ} 05^{\prime} \mathrm{N}, 05^{\circ} 41^{\prime} \mathrm{E} ; 4,379 \mathrm{ha}\right)$ and Chott Beidha $\left(35^{\circ} 55^{\prime} \mathrm{N}, 05^{\circ} 45^{\prime} \mathrm{E} ; 12,223 \mathrm{ha}\right)$ excepted of Chott Frain $\left(35^{\circ} 55^{\prime} \mathrm{N}, 05^{\circ} 40^{\prime} \mathrm{E} ; 1,500 \mathrm{ha}\right)$ [3].

2.2. Sample Collection. In the three saline wetlands, six stations were selected, with three transects on each station, and the insects were collected each month from February 2016 to November 2017 (except for December 2016 and January 2017), within halophytic plant belts surrounding directed from the periphery to the lake centre. They were selected along three transects along soil salinity gradient and vegetation cover gradient. According to [2], the soil sampling was carried out during spring season that has transitional climate characteristics between the cold-wet season and the hot-dry season. Within halophytic plant belts surrounding the Sebkha, were chosen according to the distribution of vegetation a total of 36 soil samples. Soil samples were collected at depths ranging between $0 \mathrm{~cm}$ and $20 \mathrm{~cm}$. Prior to physicochemical analysis, soil samples were crushed and dried in ambient air and then sieved to $2 \mathrm{~mm}$ in diameter. The physicochemical parameters analysed were $\mathrm{pH}$, EC: electronic conductivity (decisiemens per metre $(\mathrm{ds} / \mathrm{m})$ ), Tm: temperature $\left({ }^{\circ} \mathrm{C}\right), \mathrm{CaCo}_{3}$ : calcium carbonate (\%), OM: organic matter (\%), and gypsum(\%) to measure the soil salinity and soil organic matter, respectively, in each of the studied transect $[9,10]$.

The insect sampling methods in this study were based on $[11,12]$. Six sampling methods were used, that is, collected manually, sweep net, dip net, pitfall trap, catch moth trap, and beating tray, in each transects.

After capturing, the specimens were sorted using the stereoscopic microscope under the magnifications of $\times 2$ to $\times 4$. Identification was done on the basis of the principal morphological characteristics of each insects taxa (order level, family genera, and species), for example, thoracic pattern, wings (wing venation features and wing venation), pattern abdomen, legs, genitalia, antennae length, coloration, and number of stripes, as described by [13-17]. Large and hard insects were pinned and dried (for 15 days), and relatively small insects were mounted on paper triangles. Dry preserved samples were stored in well-sealed wooden insect boxes with naphthalene balls. Other insects were preserved in $70 \%$ ethanol + glycerin solution. Soft-bodied insects (Diptera and some species of Hymenoptera) were slide mounted using Hoyer's solution. The specimens were then extracted, dried, card mounted, and labeled. The collected specimens were kept in the Zoological Museum of the Institute for future reference.

2.3. Statistical Analysis. The species diversity indices composed as the abundance, richness index (S), Simpson's diversity index (1-D) [18], Shannon-Wiener diversity index $\left(H^{\prime}\right)$ [19], and equitability index $(E)$ [20] were calculated for each transect on each stations and sites. In addition, to computation of Jaccard similarity coefficient $(J)$ using cluster analysis was carried out using the following equation: [21]

The Jaccard similarity index $J$ was calculated according to

$$
J=\left(\frac{a}{a}+b+c\right) \times 100
$$

where $a=$ number of species of insects present at transects 1 and 2, $b=$ number of species of insects present at transect 2 and not present at transect 1 , and $c=$ number of species of Insects present at transect 1 and not found at transect 2 .

The changes in insect communities along the vegetation and salinity gradient were investigated using a factorial correspondence analysis (FCA).

All data were calculated using statistical software of Microsoft excel 2013 and Past3 (version 2013) to count ecological indices. Quantitative data, collected using questionnaire, were analysed using Statistica (Version 12) to determine FCA.

This leads to comparing the presence (abundance, etc.) of insect taxa between sites and, between stations or between transects, in order to detect, for example, differences in insect taxa composition between communities (presence/absence) and changes in the abundance of one or more insect taxa.

\section{Results}

3.1. Environmental Parameters. Soil characteristics among sites were similar throughout the study period, based on 


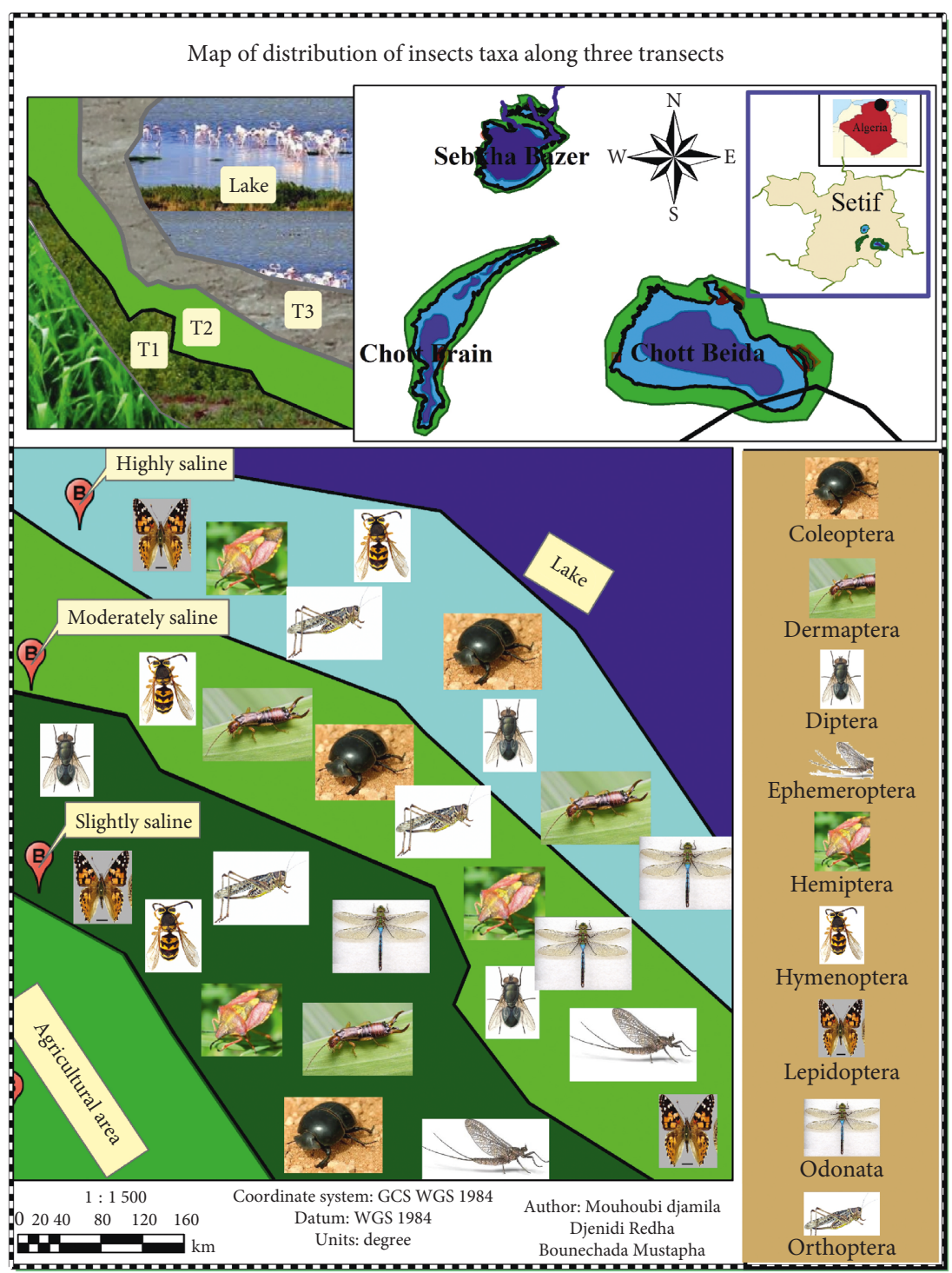

Figure 1: Map of the study area showing distribution of insects taxa points along the three transects of saline wetland in Setif region.

different physicochemical parameters (Figure 2). The present study reveals the most salty soils, with an electrical conductivity, organic matter, and $\mathrm{pH}$ of both soil of Chott and Sebkha ranging from $1.67 \mathrm{ds} / \mathrm{m}$ (BS2T16) to $118.13 \mathrm{ds} / \mathrm{m}$ (FS2T27); 0.01 (FS1T27) to 3.01 (HS1T26); and 7.13 (FS1T36) to 8.18 (BS2T26) respectively.

3.2. Species Composition. The qualitative study resulted in 9 orders of insects include to 71 families, 114 genera, and 131 species.

The results show that Coleoptera with 50 species; $38.17 \%$ in 39 genera and 19 families were the most diverse and dominant in three saline wetlands, dominated by the families of Carabidae, Chrysomelidae, Meloidae, and Tenebrionidae. The second largest insect order recorded which Hymenoptera consisted in 21 species; $16.03 \%$ in 20 genera and 11 families dominated by the families of Formicidae and Apidae. Hemiptera was the third largest insect order, with 16 species; $12.21 \%$ in 15 genera and 10 families dominated by the families of Pentatomidae, Lygaeidae, and Miridae. Orders of Diptera included 15 species; $11.45 \%$ in 15 genera and 14 families dominated by the family of Tachinidae. The Orthoptera included 10 species in 3 families and 9 genera and were dominated by the families of Acrididae and Pamphagidae with 4 species. The Lepidoptera included 9 species in 8 genera and 7 families, dominated by the family Pieridae and Geometridae 2 species. Orders of Odonata included 5 species in 3 genera and 3 families Libellulidae, Aeshnidae, and Coenagrionidae. The Dermaptera included 9 species in 8 genera and 7 families and finally the order of Ephemeroptera included 2 species in 2 genera and 2 families (Figure 3).

In Figure 4, the number of insect orders found in all three sites shows that the order of Coleoptera had the highest values in all sites and varied from 49 species in site Chott Beida 2016 to 38 species in site Chott Frain 2017, while the lowest number was recorded for Ephemeroptera which 


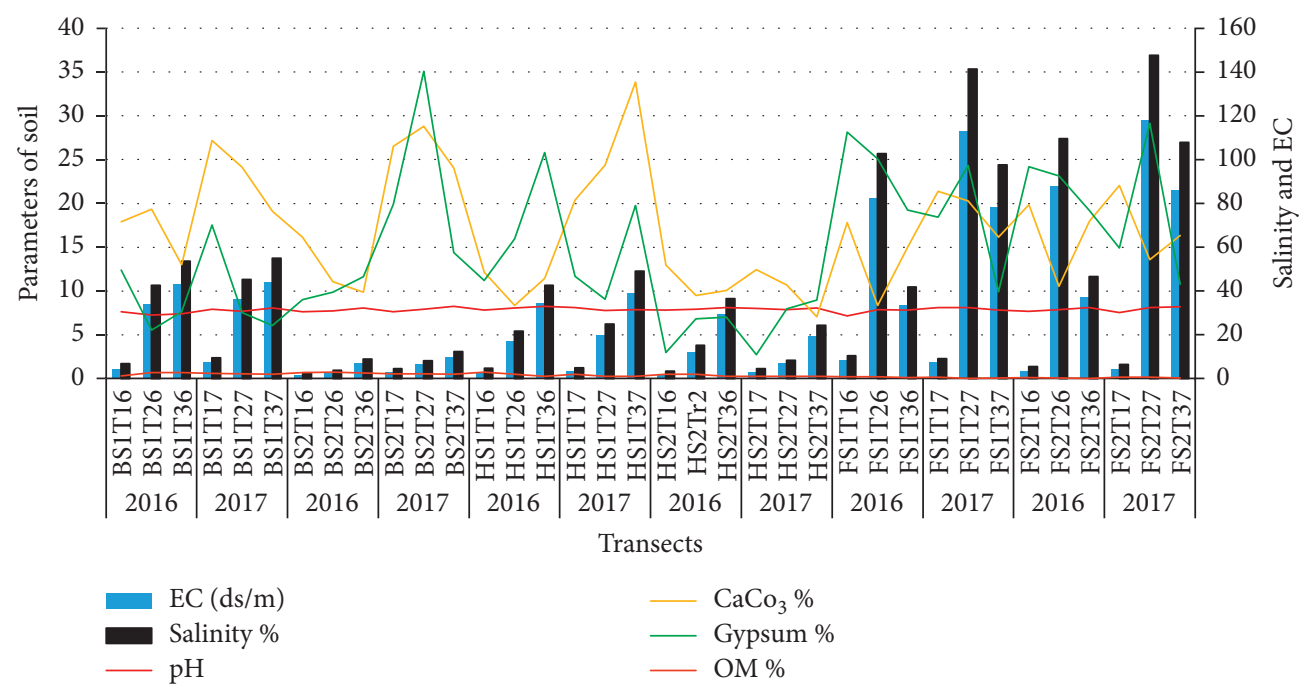

Figure 2: Characteristics of chemical soils according to transects in all sites during study period (2016-2017). (B) Sebkha Bazer, (H) Chott Beida, (F) Chott Frain, (T) Transect (T1, T2, and T3), (S) Station (S1 and S2), year: 2016 (6), year: 2017 (7).

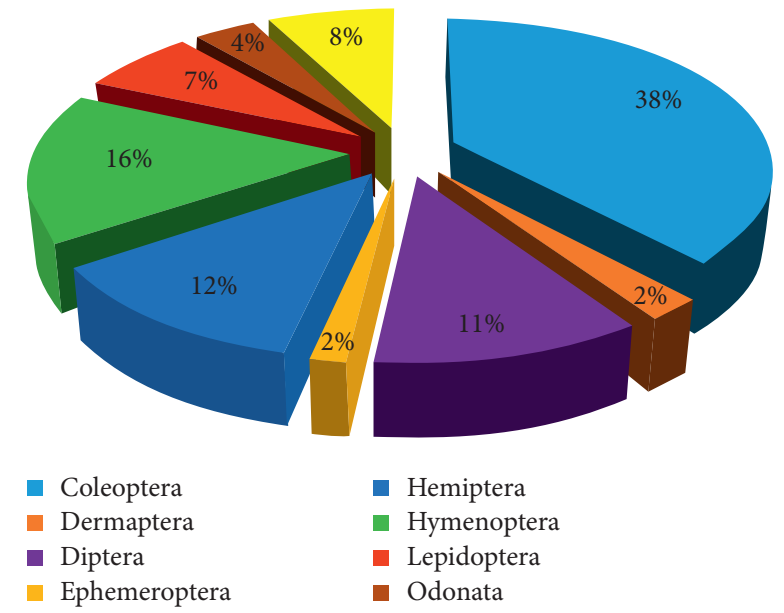

Figure 3: Percentage composition order of insects in all collected studied sites of three saline wetlands during study period (2016-2017).

ranged from 2 species in sites Sebkha Bazer 2016 and Sebkha Bazer 2017 to 0 species in sites Chott Beida 2016 and 2017 and Chott Frain 2016 and 2017.

During the present study, the insects from three sites and six different stations were compared. In the site Sebkha Bazer 2016 (B2016) recorded 126 species; 20\% with 11438 individuals followed by site Chott Beida 2016 (H2016) with 110 species; $17 \%$ and 10437 individuals and site Chott Frain 2017 (F2017) with 94 species 15\% and 4921 individuals (Figure 5). In terms of sampling stations, the highest number of individuals was recorded in BS16 (6914 ind), while the lowest number of individuals was recorded from at FS37 (2379 ind). During the present study, the insects from thirtysix different transects were compared, the highest number of species and individuals were recorded in transect 1 (BS1T16) (109 species, 2238 ind), while the lowest number of species and individuals were recorded in transect 3 (HS1T36) (6 species, 111ind).

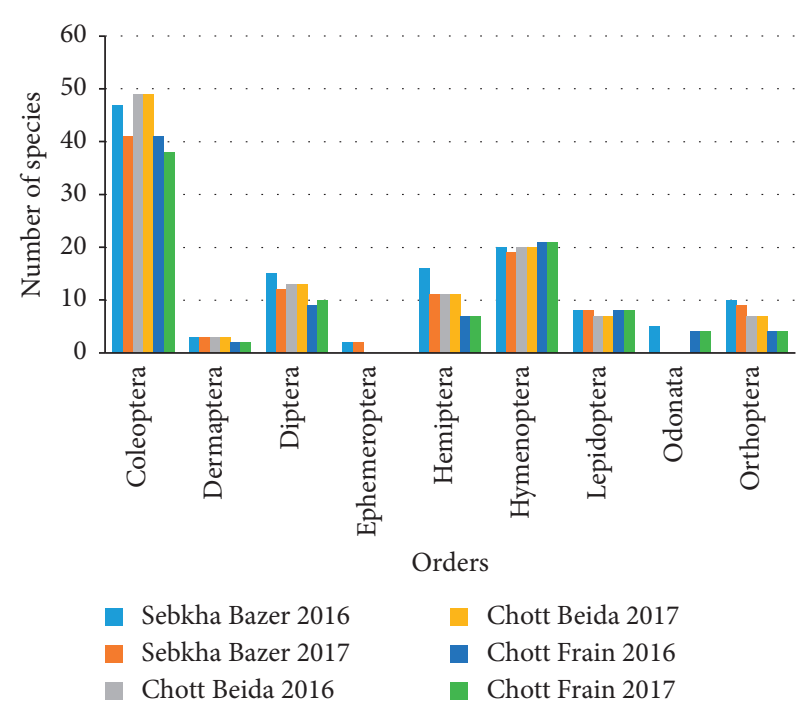

Figure 4: Number of insect taxa in all collected studied sites of three saline wetlands during study period (2016-2017).

3.3. Relative Abundance ( $R a$ ). The Formicidae family was the most abundant, constituting $61.50 \%$ of the total insects collected from all the three sites during two years of study. The maximum number of this family was recorded from site Chott Frain 2016 (71.87\%) followed by site Chott Beida 2017 (68.41\%) and site Sebkha Bazer 2016 (49.09\%), respectively. The Carabidae family constituted $11.82 \%$ towards the total number of individuals collected and was the second most relative abundance species. The maximum individuals of this family were recorded from site Chott Beida 2016 (15.92\%) and followed by site Sebkha Bazer 2016 (15.51\%) and site Chott Frain $(2.90 \%)$, respectively. The less relative abundance $(0.09 \%$ to $0.03 \%)$ species included Anax (family: Aeshnidae), Iphiclides podalirius (family: Papilionidae), Cantharis sp. (family: Cantharidae), Oulema melanopus and Oulema gallaeciana (family: Chrysomelidae), and Dasytes (family: Dasytidae). 


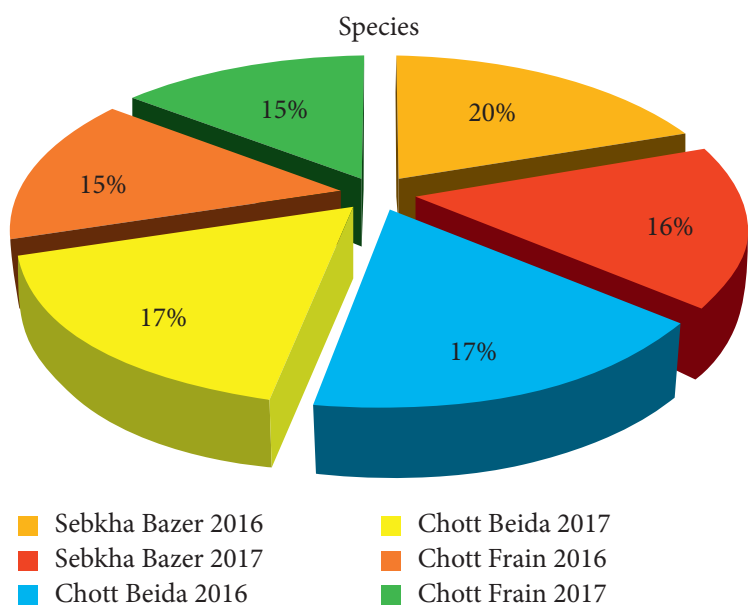

Figure 5: Percent of entomofauna according to their numbers of species in all three studied sites in saline wetlands during study period (2016-2017).

On the other hand, the species Messor barbarus had the highest relative abundance (22.65\%) while the species Oulema gallaeciana gave the lowest relative abundance $(0.02 \%)$ of the total number of individuals insects species.

In the present study, the maximum numbers of species and individuals were collected during the spring and summer season but no insects were collected during the winter season (December and January). The highest number of insects (114 species, $87.023 \%$ ) was in spring season of 2016 at BS16, and the lowest number (7 species; $5.344 \%$ ) was in the winter season (February 2017) at sites HS27 and FS27. Messor barbarous was the most abundant species comprising $17.62 \%$ of the total numbers followed by Tetramorium sp (14.55\%) and Camponotus sp (11.27\%). However, Formicidae and Carabidae were the dominant families throughout two years.

In general, Coleoptera order had the highest occurrence percentage at all seasons giving a range of $(32.06 \%)$ in spring followed by Hymenoptera. However, the lowest existence percentage was recorded for Ephemeroptera which had $(1.52 \%)$ in spring while undetected $(0 \%)$ in the three remaining seasons (Figure 6).

3.4. Biological Indices. During the present study, the insect diversity between the three sites was compared and Shannon-Wiener diversity indexes, equitability index, and Simpson index were calculated as a measure of diversity within the sites and stations and transects. The biological indices of different study sites are presented during two years in Figure 7.

During the first year, diversity indices were high at all sites and stations but a decrease was observed at the end of the second year.

3.4.1. Order Level. The diversity and value less than 1 bit are characterized as few biodiversity. In the present study, Shannon-Wiener diversity index $\left(H^{\prime}\right)$ ranges from 0 bits/ind to 3,525 bits/ind.
The diversity index $\left(H^{\prime}\right)$ of Coleoptera, Hymenoptera, and Hemiptera was 3,525 bits/ind; 2,778 bits/ind; and 2,554 bits/ind, respectively.

The Equitability index $(E)$ is a measure of the equitability with which individuals are divided among the taxa present. In the present study, the value ranges from 0 to 0.9968 . The equitability value of Dermaptera, Coleoptera, and Odonata was $0.9968,0.9944$, and 0.994 , respectively.

The highest dominance index (1-D) of insects was found for the order Coleoptera (0.9657) and least for the orders Coleoptera, Dermaptera, Diptera, Hemiptera, and Lepidoptera (0).

3.4.2. Site Level. The annual species diversity $\left(H^{\prime}\right)$ was 3,245 bits/ind and 2,981 bits/ind for the first year and the second year of the study period, respectively. The highest insect diversity was found in site Sebkha Bazer 2016, which has a Shannon-Wiener diversity index of (3,615 bits/ind), while the lowest diversity was observed in Chott Beida 2017 (2,826 bits/ind).

3.4.3. Station Level. The highest diversity ( $H^{\prime}=3,725$ bits/ ind) was observed at the second station of site Sebkha Bazer (BS26) during the first year, while the lowest diversity index was found at the first station of site Chott Beida (HS27) $\left(H^{\prime}=2,685\right.$ bits/ind) during second year. Similarly, the highest value of Simpson $(1-\mathrm{D}=0.95)$ was observed at the BS26 as compared to that of HS27 $(1-\mathrm{D}=0.8616)$ during 2016 and 2017. On the other hand, the first station of site Chott Frain (FS16) showed the lowest value of the equitability index $(E=0.5997)$ while reaching the highest value at the second station of site Sebkha Bazer (BS26) $(E=0.7823)$ during the first year.

3.4.4. Transect Level. The highest diversity index $\left(H^{\prime}=4,356\right.$ bits/ind) was observed at transect 1 (HS1T16). The lowest diversity index was found at transect 3 (HS2T36) $\left(H^{\prime}=1,619\right.$ bits/ind). Similarly, the HS2T36 showed a low value of 


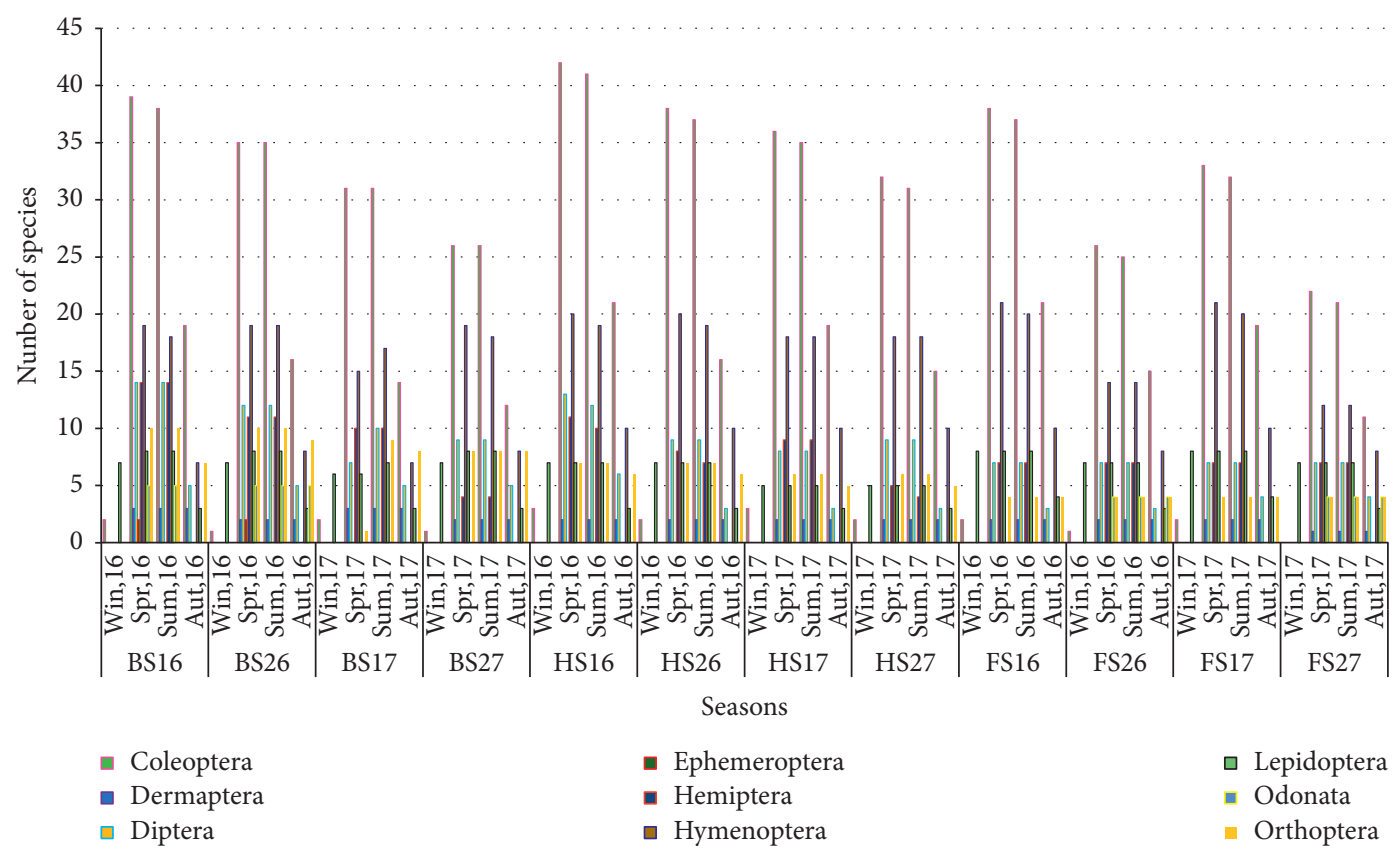

FIGURE 6: Seasonal variation of insect fauna recorded from stations during the study period (2016-2017).

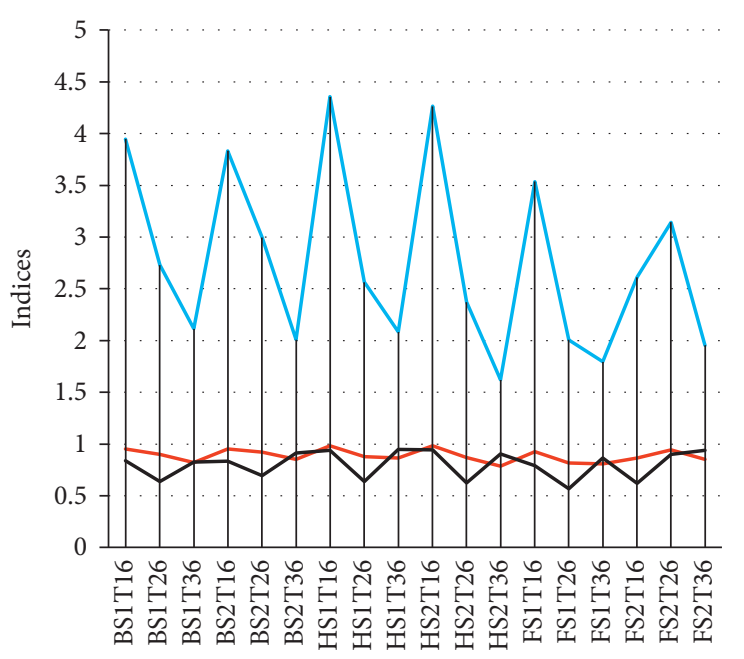

Transects

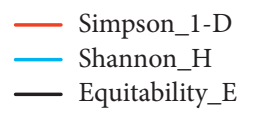

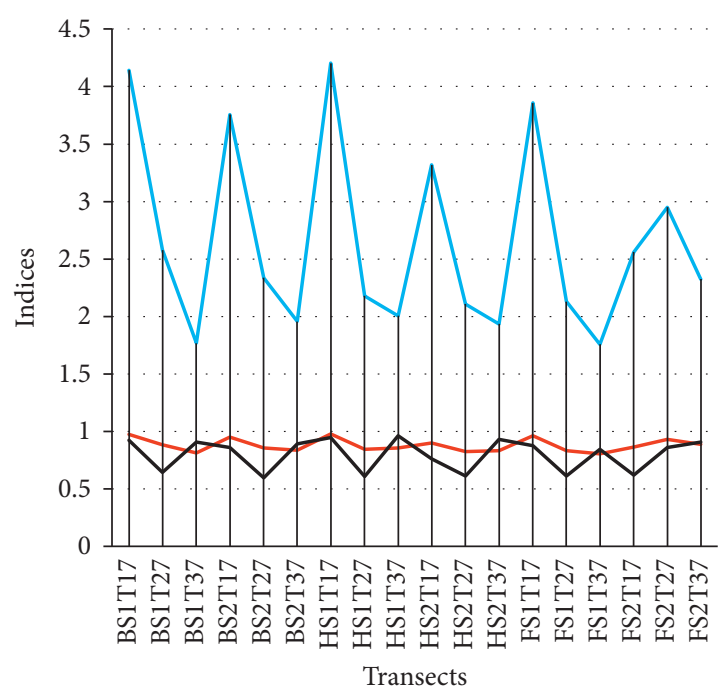

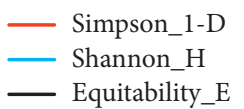

FIGURE 7: Diversity and dominance of insects in the studied transects in all sites of three saline wetlands during the study period (2016-2017).

Simpson index $(1-\mathrm{D}=0.7884)$ as compared to HS1T16 (1$\mathrm{D}=0.983)$; on the other hand, the HS1T37 showed the highest value of the equitability index $(E=0.965)$, while reaching the lowest value at FS1T26 $(E=0.5688)$.

3.5. Similarity Jaccard Index. Results showed similarities in the presence of the species between the thirty-six transects studied using the Jaccard similarity index.

However, the lowest similarity (0\%) was observed between transect FS2T37 and transects BS2T16, BS2T36,
BS1T37, BS2T37, HS1T36, HS2T36, HS1T37, HS2T37, FS1T27, and FS1T37 and transect BS2T36 and transects BS2T17, HS1T16, HS2T16, HS1T17, HS2T17, and FS2T17, while the highest similarity (1\%) was shown between transects HS1T37 and HS2T37 and transects HS1T37 and HS2T37.

Figure 8 shows the spatial distribution of insect species according to the Jaccard similarity index among them. In general, cluster analysis for similarity degree showed three different main groups, where the first main group (I) includes five subgroups, the first subgroup formed by FS1T16 


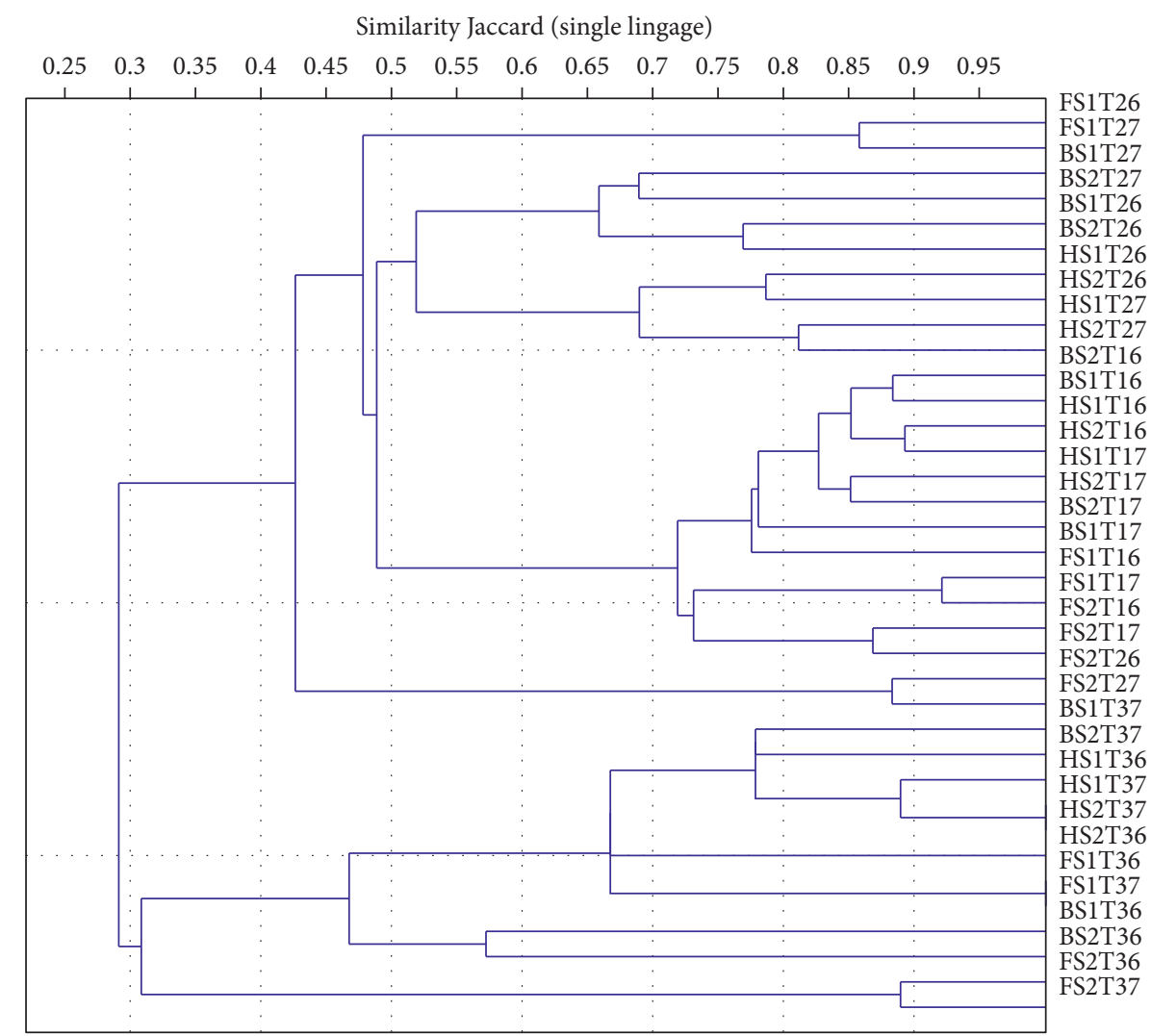

FiguRE 8: Dendrogram derived from the cluster analysis (Jaccard similarity index) during the study periods (2016-2017). Numbers T1, T2, and $\mathrm{T} 3$ attached to the transects represent the sampling stations.

and FS1T26 at the level of similarity $85.71 \%$ and the second subgroup included BS1T26, BS2T26; BS1T27, BS2T27 at the level of similarity $65.79 \%$ and the third subgroup included HS1T26, HS2T26; HS1T27, HS2T27 at the level of similarity $68.88 \%$. While the second main group (II) formed of three subgroups, the first subgroup includes BS2T16, BS1T16; HS1T16, HS2T16; HS1T17, HS2T17; BS2T17, and BS1T17 at the level of similarity $77.520 \%$ and the second includes FS1T16, FS1T17; FS2T17, FS2T16) at the level of similarity $73 \%$, while the three subgroups included FS2T27 and FS2T26 at the level of similarity $88.235 \%$. Whilst the third main group (III) also includes three of the subgroups, the first subgroup formed of FS2T36 and FS2T37 at the level of similarity $88.88 \%$, the second subgroup included BS2T36 and BS1T36 at the level of similarity $57.14 \%$, and the third subgroup included FS1T36 and FS1T37; HS2T36, HS2T37; HS1T36, HS1T37; BS1T37, BS2T37 at the level of similarity $67.86 \%$ (Figure 8 ).

The analysis of the FCA was realised on 131 species, five environmental variables (soil salinity, vegetation cover, organic matter, soil moisture, and $\mathrm{pH}$ ), and 36 transects (Figure 9), representing the spatial distribution of the species according to the environmental variable features considered.

The study of insect taxa assemblage using multivariate statistical methods FCA showed different taxa groups on the $\mathrm{F} 1$ and F2 axes plane. The first axis F1 represents $24.61 \%$, and axis $\mathrm{F} 2$ represents $17.76 \%$ from the total inertia. The distribution of the 36 transects, at the level of both F1 and F2 axes, shows the following:
F1 plane, axis 1: this means that the axis1 shows a gradient of soil salinity with vegetation cover, showing negative values for tolerant species and positive values for intolerant species.

F2 plane, axis 2: this represents mainly a gradient of soil moisture (presence/absence of water) with a vegetation gradient, showing negative values for tolerant species and positive values for intolerant species.

Considering the taxa assemblage, the diagram derived from the cluster analysis allowed three main groups to be distinguished and statistically identified by the Jaccard similarity index procedure. According to Figures 8 and 9, the main gradient in a transect as revealed by the axes 1 and 2 in Factorial Correspondence Analysis (FCA) ordination spanned of three groups situated near to themselves. A first group (1) including transect 3 (T3) was characterized by tolerant insect taxa like Amara, Calomera, Nebria, Aphaenogaster, Cataglyphis, Camponotus, Tetramorium sp, and Messor, and that related to the higher soil salinity, low organic matter, and absence of vegetation, that is situated on the right side of the axis. While the second group (2), situated in the centre of the axis marked as transect 2 (T2), is characterized by a few tolerant insect taxa such as Anthicus, Broscus, Bledius, Corixidae, Ocypus, and Calomera, it is related to the vegetation type (Halophytes) and to the soil moisture, whereas the third main third group (3) including transect 1 (T1) consisted of intolerant insect taxa such as Cordylepherus, Malachius, Berberomeloe, Meloe, Mylabris, Lytta, Bruchus, 


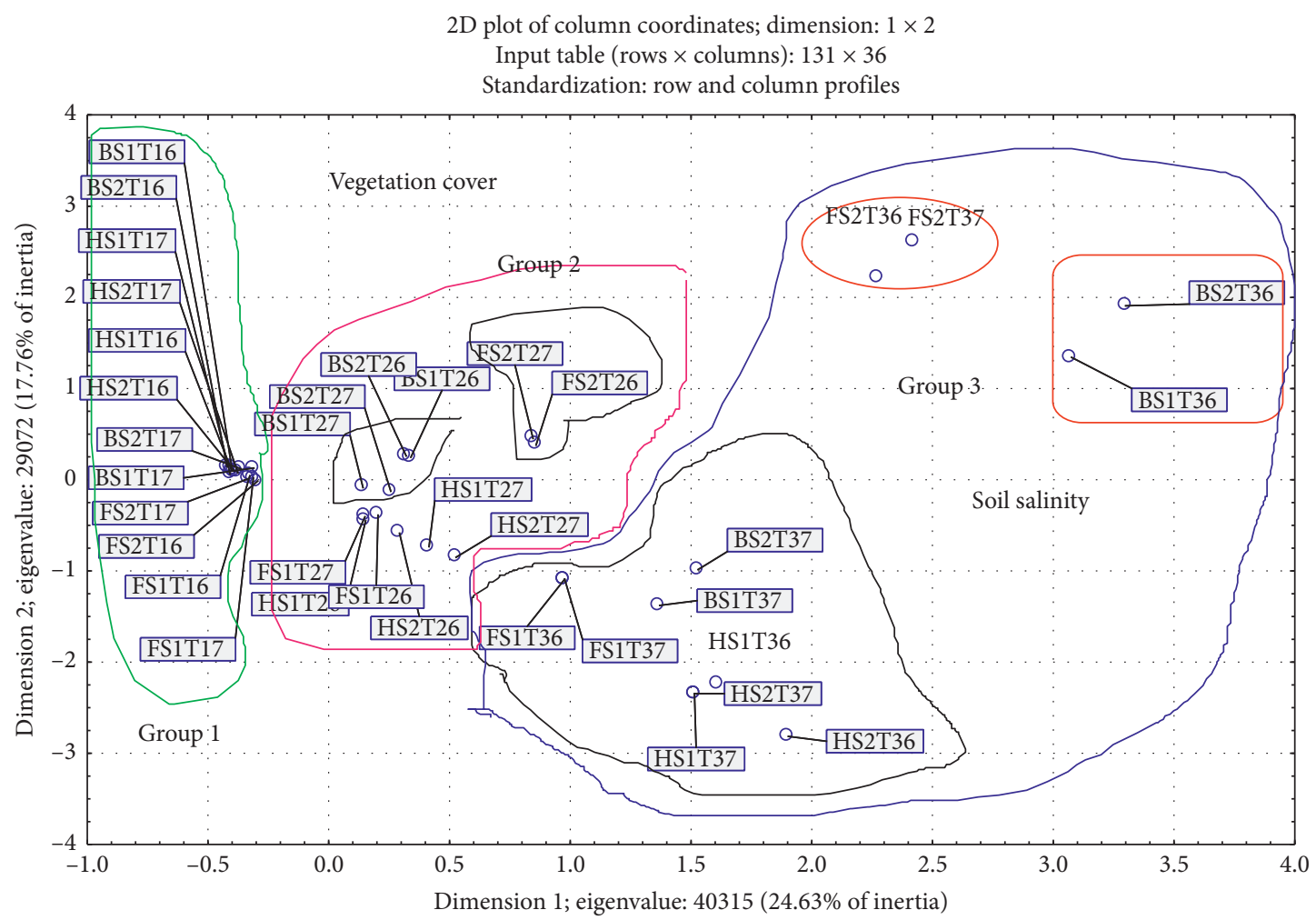

FIGURE 9: Factorial correspondence analysis (FCA) considering the abundance and distribution of the insect taxa at sites along the transect according to environmental variables.

Hemiptera, Ephemeroptera, and Acrididae; it is related to the less salinity of the soil and presence of vegetation cover that is situated on the left side of the axis.

The distribution of transects along the 1-axis corresponds to salinity of soil, whereas the transect is distributed along the 2-axis according to the abundance of vegetation cover.

\section{Discussion}

In the present study, a large variability was observed in EC values, $\mathrm{OM}, \mathrm{Tm}, \mathrm{pH}, \mathrm{CaCo}_{3}$, and gypsum, within each transects and between stations, revealing that most soils in the selected locations were sandy to loamy sandy or loam soil, and soils of the study sites were moderately calcareous with $\mathrm{CaCO}_{3}=20.40 \%$ and gypsum $=15.40 \%$ and the soils in the study area might be considered as slightly alkaline in all the selected locations; generally, the organic matter was low in the samples of soil analysed and showed three different transect parts (T1, T2, and T3) with values averaged to be $\mathrm{EC}=4.26 \mathrm{ds} / \mathrm{m}$ that included transect 1 ; in addition, soils of these sites were salty to very salty, and they are followed by transect 2, where EC values averaged to $38.43 \mathrm{ds} / \mathrm{m}$; soils of this transect were very salty to extremely salty, while the transect 3 recorded the highest EC values averaging to $44.72 \mathrm{ds} / \mathrm{m}$ that correspond to extremely salty soils.

In the light of the results obtained after the analysis of three transects in each station, these results agree in general with some other studies although it significantly varies from one sites to another and from one transect to another [22, 23].
4.1. Species Composition. The inventory of entomofauna let us count 131 species of the total number of all species of insects distributed on 9 orders, belong to 114 genus and follow 71 families. These results agree in general with some other studies that were conducted in different places in the Algeria and other parts of the world about the biodiversity in saline wetlands, and these studies include [24-28].

The results of the recent study shows the predominance of Coleoptera order, with a percentage of $38 \%$ of the total of the insect species; this is due to the diversity of species in order Coleoptera because they adapted in all terrestrial and aquatic environments or because of their morphological characteristics [29]. Many studies showed the predominance of order Coleoptera $[1,26,30]$. Also, the recent studies show the predominance of the following families (Chrysomelidae and Carabidae), $8 \%$ of the total of species order Coleoptera; however, this percentage was less compared with other studies carried out about the entomological biodiversity of salt wetlands such as in study [27], where thay have been found to have generally higher or at least similar species numbers as on our study. In addition to other species related to order Hymenoptera (Formicidae), this enrolled 5\% of the total of order Hymenoptera in the results of our study, and they agree in general with other results of other studies about the diversity of order Hymenoptera in the saline wetlands $[1,27]$.

Our results showed that some species of Hemiptera, Diptera, and Lepidoptera such as Vanessa cardui, Pieris rapae, Pieris brassicae, and Culex pipiens were recorded in different transects. According to [31-34], Hymenoptera, Coleoptera, 
and Diptera are reported as ecologically tolerant and has an extensive geographical range in all types of environments, whereas those species of insects which were rare in abundance at transect 3 such as Halictus sp, Chrysis sp (Hymenoptera), Pamphagus sp (Orthoptera), and Ephemeroptera may have narrow range of tolerance to these environmental conditions (salinity and lack of vegetation) [35].

4.2. Spatial Distribution. In our study, the results show that the diversity of insect community structure changed in response to environmental gradients (biotic and abiotic), and according to our study of transects in each stations of Sebkha and Chott, high interspecific association existed in species that had co-occurrence in a number of individuals and rare species that were found in transect 2 or transect 3. Fifteen genera, Carabidae (Amara, Bembidion, Broscus, Calomera, and Nebria), Chrysomelidae (Labidostomis, Lachnaia, and Longitarsus), Staphylinidae (Bledius and Ocypus), and Formicidae (Aphaenogaster, Cataglyphis, Camponotus, Tetramorium sp, and Messor) occurred in the transect 2 and transect 3, reflecting their robust adaptability to saline habitats (soil type and water). Although five common genera, Aphaenogaster, Cataglyphis, Camponotus, Tetramorium sp., and Messor, were limited to the Sebkha edge and the Sebkha interior, they occurred in most abundance of the transect 2, indicating that the vegetation and soil type might act as an environmental factor for their distribution. The fifteen insect taxa detected as rare species with unique occurrence in the transect 2 or 3 demonstrated high habitat specificity according to $[35,36]$. This pattern in distribution of species abundances is accompanied on a larger-scale level by the tendency of widespread species to also occur in higher densities compared to species restricted to their geographic distribution.

On the other hand, the transect 1 shows high diversity mainly due to the low soil salinity and high-density plants, which constitute one of the most restricting factors for the insect fauna, leading to highest abundances and richness species, which is composed of more than one species and other insect taxa and dominated by Coleoptera and Hemiptera families [36].

4.3. Seasonal Variations. As for seasonal variation, some insect taxa such as Amara, Nebria, Bledius, Ocypus, Camponotus, Messor, Aphaenogaster, Vanessa, Pieris, Halictus, Malachius, Meloe, Mylabris, and Lytta clearly vary among seasons, in relation to the abundance of all the taxa observed at each study site. Values of number of species and abundance of insect taxa increase the values of insect diversity and richness indices in Sebkha Bazer compared to Chott Beida and Chott Frain, assuming that the same inventory effort was applied at the three saline wetlands. However, the seasonal analysis showed a predominance of insect taxa during spring season that may due to the effect of several factors on diversity of species, which include environmental factors like moderation in temperature, salinity, and moisture. These results agreed with $[37,38]$. On the other hand, a higher abundance of Hymenoptera and some species of Coleoptera family was observed in these seasons, in each of Chott Beida 2017 (comprised 22.65\%), but its abundance in Chott Frain 2016 was 20.75\% and in Sebkha Bazer 2017 it was 18.17\%. But, other species in Chott Frain 2017 and Chott Beida 2017 appeared in low abundance, such as Oulema melanopus, Oulema gallaeciana, Lixus algirus, Dasytes sp, Tabanus sp, and Carpocoris purpureipennis.

4.4. Ecological Indices. The spatial variation for ecological indices for insect community in saline wetlands showed that the annual overall value of diversity index was 3,723 bits/ind which was calculated from 131 species in all three sites.

The values that were nearly between $\left(H^{\prime}=4.35-1,919\right.$ bits/ind), ( $1-\mathrm{D}=0.95-0.78)$, and $(E=0.965-0.568)$ calculated from different sites and stations, and our study indicates the existence of species richness and this represents diverse and well-distributed community in these sites. These results agree in general with some other studies $[1,27]$.

The ecological indices vary between $\left(H^{\prime}=3.52-0\right.$ bits/ ind), (1-D =0-0.96), and ( $E=0-0.996)$. These wide differences of values coupled with their spatial and temporal variations reflect the heterogeneity of insect communities. And, according to the study of diversity of order species between the sites, stations, and transects, the result was found to be very low at transect 3 in all stations as compared to the transects 1 and 2 (T1 and T2). This could be attributed to disturbances occurring in the transect 3 (T3) and may be a loss of diversity which has a special type of halophyte plant species such as Atriplex, Salsola, Juncus, and Suaeda. Another reason could be explained by the high level of soil salinity gradient and low organic matter (OM) content causing loss of some of species of insects, in addition to climatic factors and disturbances such as droughts. That is what we see in sites Chott Beida (2017) and Chott Frain (2016 and 2017).

4.5. Similarity Jaccard Index and Factorial Correspondence Analysis (FCA). According to the results of similarity Jaccard analysis and FCA, three major groups were delineated, which were mainly segregated based on the abundance and diversity towards environmental parameters (Figures 7 and 8). The criterion spatial distribution of insect taxa can be interpreted as the difference in environmental gradients (soil salinity and vegetation cover). The FCA plot shows gradients of intolerant insect taxa in the transect 1 to tolerant species. Group 1 consisted of increased diversity, richness, and abundance of insect taxa observed in the transect 1 . This is may be due to its location near the edge of the Sebkha and Chott of cereal crops, sparse vegetation, and low soil salinity. While the reason behind the low richness and diversity of insect taxa in the transect 3 may be due to the absence of vegetation and increased soil salinity. The difference in environmental gradients is in accordance with the findings of other authors such as in [1].

\section{Conclusion}

According to the results, abundances of insect fauna show a decreasing gradient of the transect 1 to transect 3 , and the 
results showed the influence of the vegetation cover and salinity gradient on the composition of the insect fauna community.

From this study, the saline wetlands of the high plain region in Setif are still considered to have a diverse and numerous insect fauna in this area. However, the results which were being presented in this paper might be the first comprehensive list of insects in the saline wetlands in Setif region. Hopefully, there will be a further research study on the insect biodiversity and taxonomy in this area, in order to get better and comprehensive information on those aspects to be documented for future reference.

\section{Data Availability}

Data used to support the findings of this study are available from the corresponding author upon request.

\section{Disclosure}

This study is a part of $\mathrm{PhD}$ thesis by Mouhoubi Djamila (2014-2019) supported by research supervisors Prof. Djenidi Redha and Prof. Bounechada Mustapha. In addition, the abstract was presented as poster presentation in the 3rd International Symposium on EuroAsian Biodiversity (as part of the $\mathrm{PhD}$ thesis).

\section{Conflicts of Interest}

The authors declare that they have no conflicts of interest.

\section{Acknowledgments}

The authors thank Prof. Djenidi Redha who participated in the sampling site selection and revising this manuscript. The authors thank Prof. Mustapha Bounechada for species determination and valuable comments on the faunistic parts of the manuscript. The authors would also like to thank the Chief Conservator and Director of Forest, Setif, for allowing us to conduct this study. And also, they wish to thank Tahar Chenni, Chief Conservator of Forest, el Eulma, for his help with the field work.

\section{References}

[1] D. Mouhoubi, R. Djenidi, and M. Bounechada, "Contribution to the study of entomofauna of the saline wetland of Chott Beida in Algeria," Journal of Entomology and Zoology Studies, vol. 6, no. 4, pp. 317-323, 2018.

[2] M. Khaznadar, I. N. Vogiatzakis, and G. H. Griffiths, "Land degradation and vegetation distribution in Chott El Beida Wetland, Algeria," Journal of Arid Environments, vol. 7, no. 33, pp. 369-377, 2009.

[3] MADR-DGF, Ministère de l'Agriculture et du Développement Rural-Direction Générale des Forêts: ATLAS [IV] des Zones Humides Algériennes d'importance Internationale, 2004.

[4] M. J. Westfall, Jr. and K. J. Tennessen, "Odonata," An Introduction to the Aquatic Insects of North America, vol. 3, pp. 164-211, 1996.

[5] M. Pouget, Les Relations Sol-Végétation dans les Steppes SudAlgéroises, ORSTOM, Paris, France, 1980.
[6] A. Bennett, "The role of soil community biodiversity in insect biodiversity," Insect Conservation and Diversity, vol. 3, pp. 157-171, 2010.

[7] C. Piscart, J.-C. Moreteau, and J.-N. Beisel, "Biodiversity and structure of macro invertebrate communities along a small permanent salinity gradient (Meurthe river, France)," Hydrobiologia, vol. 551, no. 1, pp. 227-236, 2005.

[8] ONM, Relevés météorologiques de l'année 2017, Office National de Météorologie, SFIHA, Setif, Algeria, 2017.

[9] D. Baize, Guide of Pedological Analyses: Choice, Expression, Presentation, Interpretation, INRA, Paris, France, 2nd edition, 2000.

[10] M. Pansu and J. Gautheyrou, Handbook of Soil Analysis: Mineralogical Organic and Inorganic Methods, Springer, Berlin, Germany, 2006.

[11] J. E. H. Martin, Collecting, Preparing and Preserving Insects, Mites, and Spiders. The Insects and Arachnids of Canada, Canada Department of Agriculture, Ottawa, ON, USA, 1977.

[12] M. L. Benkhelil, Les Techniques de Récolte et de Piégeage Utilisées en Entomologie Terrestre, University of Algiers, Algiers, Algeria, 1991.

[13] A. Hoffmann, Faune de France: Coléoptères Curculionides, 3ème partie, Lechevalier, Paris, France, 1958.

[14] M. Roth, Initiation a la morphologie, la systgmatique et la biologie des insectes, ORSTOM, Paris, France, 1980.

[15] J. C. Pihan, Les Insectes, Masson, Paris, France, 1986.

[16] W. Stichmann, Faune d'Europe, Vigot, Paris, France, 1999.

[17] G. Laplanche, Papillons de Méditerranée, Edisud, Aix-enProvence, France, 2008.

[18] E. H. Simpson, "Measurement of diversity," Nature, vol. 163, no. 4148 , p. 688, 1949.

[19] C. E. Shannon and W. Weaver, The Mathematical Theory of Communication, Urbana, University of Illinois Press, Champaign, IL, USA, 1949.

[20] E. C. Pielou, "The measurement of diversity in different types of biological collections," Journal of Theoretical Biology, vol. 13, pp. 131-144, 1966.

[21] P. Jaccard, "Nouvelles recherches sur la distribution florale," Bulletin de la Société vaudoise des Sciences Naturelles, vol. 44, pp. 223-270, 1908.

[22] S. Neffar, H. Chenchouni, and A. Si Bachir, "Floristic composition and analysis of spontaneous vegetation of Sabkha Djendli in North-East Algeria," Plant Biosystems-An International Journal Dealing with All Aspects of Plant Biology, vol. 150, no. 3, pp. 396-403, 2016.

[23] H. Chenchouni, "Edaphic factors controlling the distribution of inland halophytes in an ephemeral salt lake "Sabkha ecosystem" at North African semi-arid lands," Science of the Total Environment, vol. 575, pp. 660-671, 2017.

[24] A. Si Bachir, "Etude bioécologique de la faune du lac de boulhilet ou petit ank djamel (Oum el Bouaghi)," Thesis, Setif 1 University, Sétif, Algeria, 1991.

[25] G. Aydin, "Vulnerability of Megacephala (grammognatha) euphratica euphratica latreille \& dejean, 1822 (Coleoptera: cicindelidae) in natural and disturbed salt marsh and salt meadow habitats in Turkey," African Journal of Biotechnology, vol. 10, no. 29, pp. 5692-5696, 2011.

[26] S. Boukli-Hacene, K. Hassaine, and P. Ponel, "Les peuplements des coléoptères du marais salé de l'embouchure de la Tafna (Algérie)," Review of Ecology-Earth and Life, vol. 66, 2012.

[27] H. Chenchouni, T. Menasria, S. Neffar et al., "Spatiotemporal diversity, structure and trophic guilds of insect assemblages in a semi-arid Sabkha ecosystem," PeerJ, vol. 3, p. e860, 2015. 
[28] P. Maity, S. Roy, U. Chakraborti et al., "Insect faunal diversity of Salt Lake City-an urbanized area adjacent to Kolkata, India," Bioscience Discovery, vol. 7, no. 2, pp. 101-112, 2016.

[29] R. Dajoz, Précis d'écologie: Cours et Questions de Réflexions, Dunod, Hachette Livre, France, 8ème edition, 2006.

[30] R. Matallah, K. Abdellaoui-Hassaine, P. Ponel, and S. Bouklihacene, "Diversity of ground beetles (Coleoptera carabidae) in the ramsar wetland: dayet el ferd, Tlemcen, Algeria," Biodiversity Journal, vol. 7, no. 3, pp. 301-310, 2016.

[31] A. D. Padhye, N. Dahanukar, M. Paingankar, M. Deshpande, and D. Deshpande, "Season and landscape wise distribution of butterflies in Tamhini, Northern Western Ghats, India," Zoos' Print Journal, vol. 21, no. 3, pp. 2175-2181, 2006.

[32] S. Carver, A. Storey, H. Spafford, J. Lynas, L. Chandler, and P. Weinstein, "Salinity as a driver of aquatic invertebrate colonisation behaviour and distribution in the wheat belt of Western Australia," Hydrobiologia, vol. 617, no. 1, pp. 75-90, 2009.

[33] T. D. Zinchenko and L. V. Golovatyuk, "Salinity tolerance of macro invertebrates in stream waters (review)," Arid Ecosystems, vol. 3, no. 3, pp. 113-121, 2013.

[34] F. Perveen, A. Khan, and Sikander, "Characteristics of butterfly (Lepidoptera) fauna from Kabal, SWAT," Pakistan Journal of Entomology and Zoology Studies, vol. 2, no. 1, pp. 56-69, 2014.

[35] W. Verberk, "Explaining general patterns in species abundance and distributions," Nature Education Knowledge, vol. 3, no. 10, p. 38, 2011.

[36] R. Jaskula, M. P1óciennik, and A. Schwerk, "From climate zone to microhabitat-environmental factors affecting the coastal distribution of tiger beetles (Coleoptera: cicindelidae) in the south-eastern European biodiversity hotspot," PeerJ, vol. 7, p. e6676, 2019.

[37] B. V. Timms, "On the influence of season and salinity on the phenology of invertebrates in Australian saline lakes, with special reference to those of the Paroo in the semiarid inland," Journal of Oceanology and Limnology, vol. 36, no. 6, pp. 1907-1916, 2018.

[38] W. D. Williams, P. De Deckker, and R. J. Shiel, "The limnology of Lake Torrens, an episodic salt lake of central Australia, with particular reference to unique events in 1989," Hydrobiologia, vol. 384, no. 1-3, pp. 101-110, 1998. 


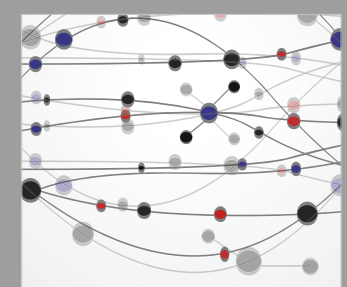

The Scientific World Journal
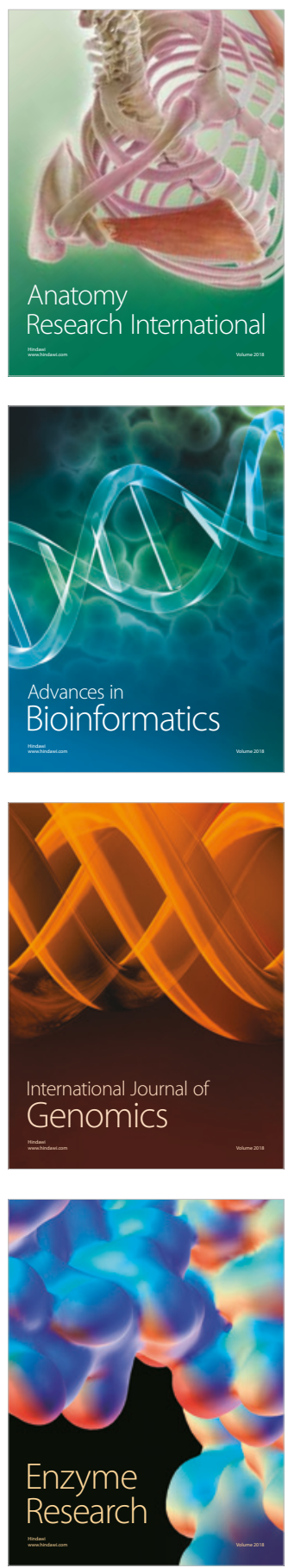
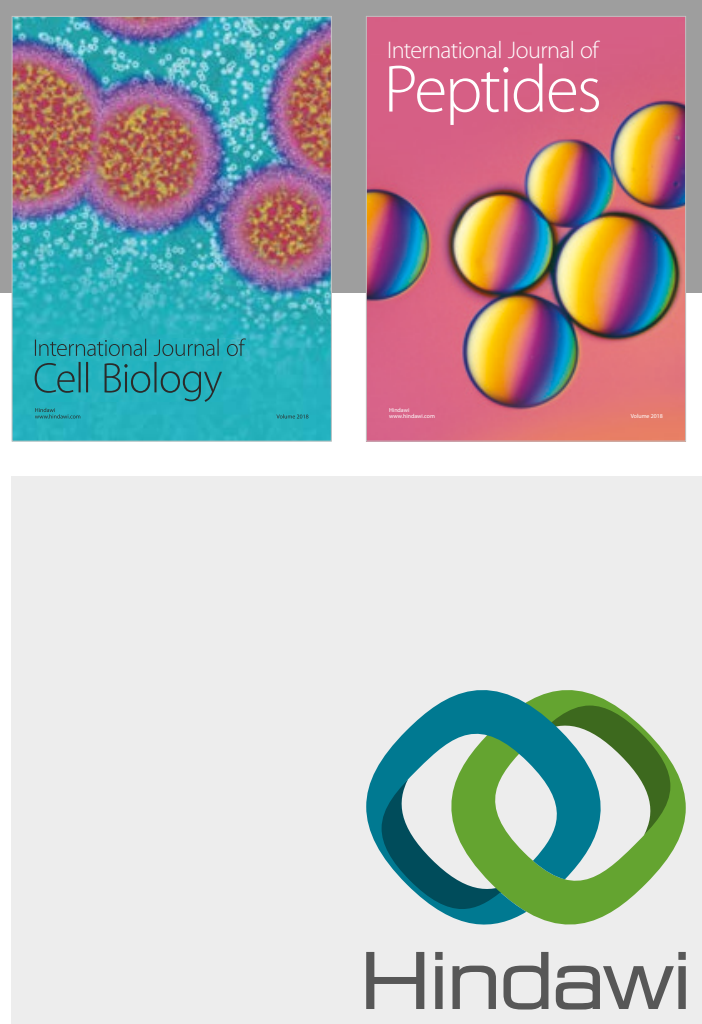

Submit your manuscripts at

www.hindawi.com
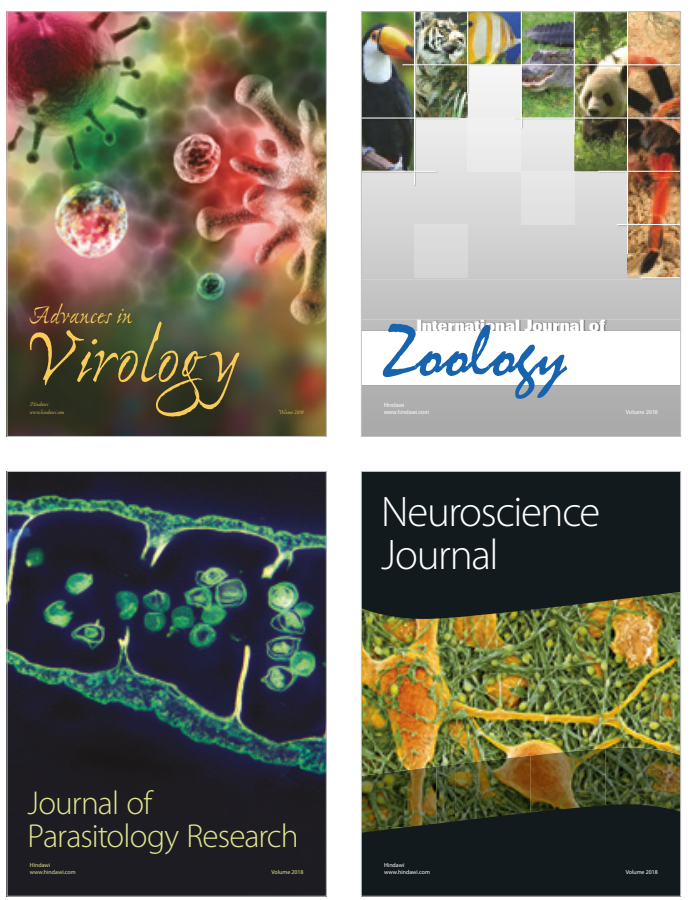
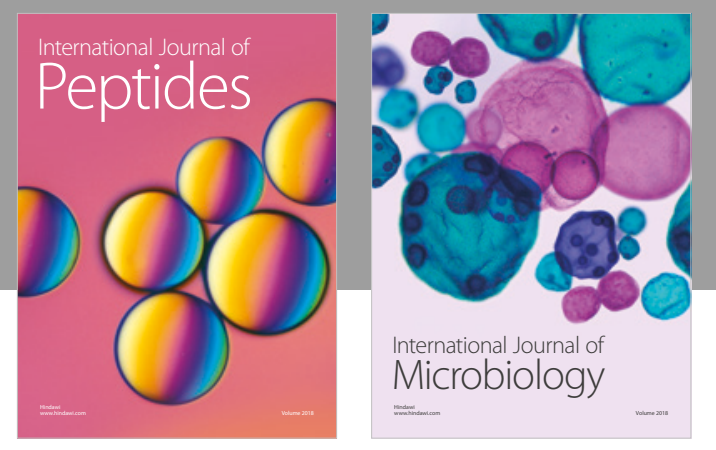

nternational Journal of Microbiology
Journal of
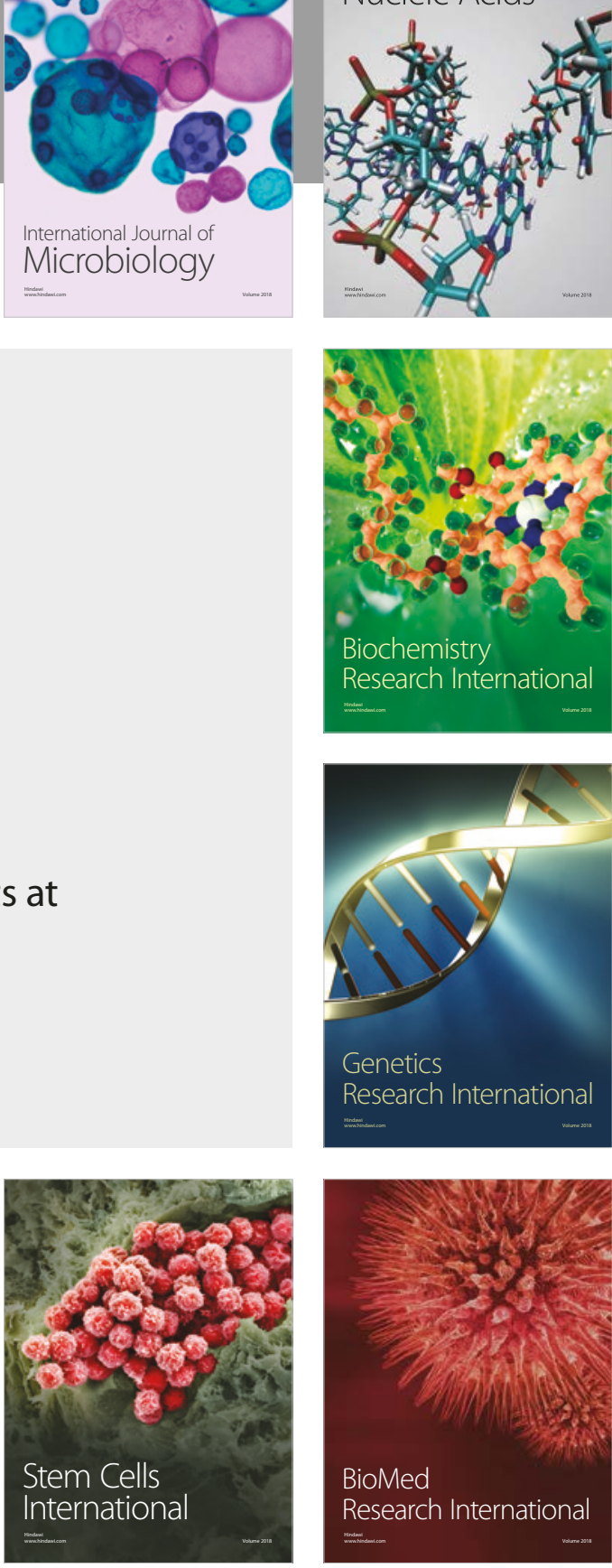
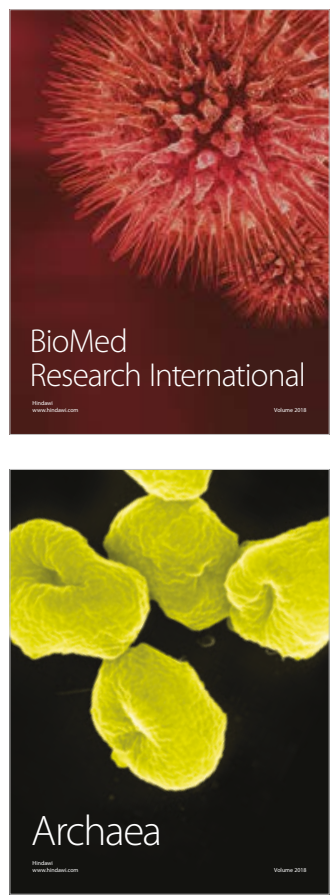